\title{
ANN Analysis of Injection Timing on Performance Characteristics of Compression Ignition Engines Running on the Blends of Tropical Almond Based Biodiesel
}

\author{
Samson Kolawole Fasogbon, Olusegun Oladapo Laosebikan, Chukwuemeka Uguba Owora* \\ Department of Mechanical Engineering, University of Ibadan, Ibadan, Nigeria \\ Email address: \\ sk.fasogbon@ui.edu.ng (S. K. Fasogbon), segunrules@yahoo.com (O. O. Laosebikan), chukwuemeka.owora@gmail.com (C. U. Owora) \\ ${ }^{*}$ Corresponding author
}

\section{To cite this article:}

Samson Kolawole Fasogbon, Olusegun Oladapo Laosebikan, Chukwuemeka Uguba Owora. ANN Analysis of Injection Timing on Performance Characteristics of Compression Ignition Engines Running on the Blends of Tropical Almond Based Biodiesel. American Journal of Modern Energy.Vol. 5, No. 2, 2019, pp. 40-48. doi: 10.11648/j.ajme.20190502.16

Received: March 20, 2019; Accepted: April 27, 2019; Published: June 20, 2019

\begin{abstract}
In the present work, biodiesel prepared from Tropical almond oil (Terminalia Catappa) was used as fuel in C. I engine. Performance studies were conducted on a single cylinder four-stroke water-cooled compression ignition engine. Experiments were conducted for different percentage of blends of Tropical almond ester with diesel at different injection timings. Experimental investigations on the performance parameters from the engine were done. Artificial neural network (ANN) of back-propagation feed-forward Levenberg-Marquardt algorithm was used to predict the performance characteristics of the engine. An ANN model was developed for the performance parameters. To train the network, blend percentage, percentage load and injection timings were used as the input variables whereas engine performance parameters (brake thermal efficiency, exhaust gas temperature, and brake specific fuel consumption) were used as the output variables. The obtained experimental results were used to train the network structure. Results showed very good correlation between the ANN predicted values and the desired values for various engine performance values. Mean relative error values were less than 10 percent which by many standards is acceptable. The results show that ANN is an accurately reliable tool for the prediction of engine performance.
\end{abstract}

Keywords: Tropical Almond Ester, Injection Timing, Artificial Neural Network, Blend Percentage, Percentage Load, Brake Thermal Efficiency, Exhaust Temperature, Brake Specific Energy Consumption

\section{Introduction}

The agricultural sector in Nigeria is completely dependent on diesel for its power and to some extent for stationary applications. Increased farm mechanization in agriculture thus, has further increased the requirement of diesel. Nowadays due to the limited resources of fossil fuels, rising crude oil prices and the increasing concerns for the environmental security, there has been renewed focus on vegetable oils and animal fats as alternative fuel sources. The attractive features of the biodiesel are: (i) since it is a plant derived fuel, its combustion does not increase the current net atmospheric levels of $\mathrm{CO}_{2}$, a greenhouse gas (ii) it can be locally produced, thus, providing opportunity for the possibility of reducing petroleum importation and (iii) it is biodegradable, renewable and burns with clean gas. In most of the developed countries sunflower, peanut, palm and several other feed stocks are used as alternative sources. Therefore, in developing countries like Nigeria, it is desirable to produce biodiesel from oils which can be extensively grown throughout the country. It has been reported that almond oil is readily available in Nigeria. However, the major disadvantage of vegetable oils is their high viscosity which leads to poor atomization, which in turn may lead to poor combustion, ring sticking, injector coking, injector deposits, injector pump failure and lubricating oil dilution by crank case polymerization. [1-3] observed that converting vegetable oils into simple esters is an effective way to overcome all the problems associated with the vegetable oils. The conversion of vegetable oil into alkyl esters is 
called transesterification. The transesterification process reduces the viscosity of the oil through the removal and replacement of glycerine with radicals of the alcohol [4]. Biodiesel fuels possess physicochemical properties that are similar to fossil based diesel [5] and can be used in compression ignition engine without modification; and it has been identified as a good alternative renewable fuel [6,7].Based on feedstock, there exist four groups of biofuels and they are: first, second, third, and fourth generation biofuels [8]. Generally, first and second generation biofuels are the most produced biofuels in recent times. First generation biofuels are derived from starch and sugar based crops (e.g. sugar cane, wheat, barley, rice etc.); while the second generation biofuels are derived from non-edible feed stocks such as agricultural residues (e.g. lemon peel, corn waste etc.), waste products (e.g. waste cooking oil), lignocellulosic plant biomasses, and plant oil containing seeds (croton megalacorpus tropical almond etc.). The third and fourth generation biofuels are obtained from microalgae biomass feedstock and genetically modified algae biomasses respectively. Problems associated with the commercialization of third and fourth generation biofuels are insufficient biomass production, low intensity of solar radiation partly due to season, and complexity and cost of harvesting microalgae [5, 8, 9-13]. Main problems attributed to the application of first and second generation biofuels include food crises and land availability since they are produced from crops [14-18]. Therefore, the use of tropical almond which is not a major food plant to produce biodiesel solves the issue of food-versus-fuel argument.

For a diesel engine, fuel injection timing is a major parameter that affects combustion and exhaust emissions. Proper ignition delay is necessary for ensuring proper pressure rise and peak pressure and hence maximum thermal efficiency, which in turn depends on the type of fuel also. [19] conducted experiments in a dual fuel CI (Compression ignition) engine to study the effect of injection timings on the exhaust emissions. They used ethanol blends with diesel and conducted experiments at five different injection timings. They observed that $\mathrm{NOx}$ and $\mathrm{CO} 2$ emissions increased and $\mathrm{HC}$ and $\mathrm{CO}$ emissions reduced for advanced injection timing. [20] carried out experiments on a single cylinder diesel engine with natural gas as the fuel. On advancing injection timing by $5.5^{\circ}$ the engine showed erratic performance and when it was reduced to $3.5^{\circ}$ he observed a smooth performance especially at low load conditions. Fuel consumption was slightly increased whereas $\mathrm{CO}$ and $\mathrm{CO} 2$ emissions were reduced. Similarly, second generation biofuels which tropical almond biodiesel belongs have been largely applied in operating internal combustion engines. The following works show how fuels derived from plant sources have been used to run CI engines. Ashok et al., [21] applied orange peel oil of $20 \%$ to evaluate performance and emission characteristics of a CRDi engine. The evaluation showed improved performance with the use of biodiesel than conventional diesel fuel. The biodiesel produced higher brake thermal efficiency, mechanical efficiency and lower brake specific energy consumption under almost every operating conditions, especially injection timings. Ashok et al., [22] investigated the performance and emissions effects of $20 \%$ lemon peel oil operating a CRDI. Brake thermal efficiency, mean gas temperature and brake specific fuel consumption showed significant positive improvement at all operating conditions. The brake thermal efficiency improved by $33.3 \%$ more than that of diesel. Kumar et al., [23] investigated the performance and emissions profiles of lemon peel oil methyl ester blends on CI engine. The brake thermal efficiency showed higher improvement. The improvement was attributed to premixing and ignition delay. The brake specific fuel consumption was lower when biodiesel was used; and a necessary factor to associate it was high oxygen content of the biodiesel. Ashok et al., [24] made a comparative assessment of orange and lemon peel oil biofuels. The assessment shows both performance and emission parameters improved in significant amount. In all of that, the improved performance was basically associated to higher oxygen content, lower cetane number, and delayed ignition.

Manufacturers and engine application engineers usually intend finding out the performance of a C. I engine for various proportions of blends, for various compression ratios and at different injection timings. This requirement can be met either by conducting comprehensive tests or by modelling the engine operation. Testing the engine under all possible operating conditions and fuel cases are time consuming, costly and complex. On the other hand, developing an accurate model for the operation of a C.I engine fueled with blends of biodiesel is too difficult due to the complex nature of the processes involved. As an alternative, engine performance and exhaust emissions can be modelled by using artificial neural network (ANN). This modelling technique can be applied to estimate the desired output parameters when enough experimental data is provided. In the present work, experimental investigations of the performance and emissions of the diesel engine were conducted for different proportions of blends of tropical almond oil with diesel at different injection timing. subsequently, ANN models of multilayer perceptron (MLP) were developed and applied in predicting the performance characteristics using those experimental results. Among current estimation models used in performing data analysis, ANN possesses the best capabilities or qualities [23] and the multilayer perceptron (MLP) ANN structure is the most applied. Artificial neural network innovation was derived from the concept of human neurological system. It consists input layer neurons, hidden layer neurons, and output layer neurons, which are interconnect through a connecting weight [2527]. Each of the layers contains neurons that are linked to the neurons of the next layers through weight interconnection. The input layer neurons without making 
computation send input signals to the hidden layer neurons. All the hidden layer neurons make individual summation of all the inputs in such a way that once the combined summation is higher than activation value, the network produces an output. For any declared input, activation flow is transported from input layer to output layer via hidden layer [28]; and the process may be repeated as determined by error values. The errors are back-propagated into the neural network until it is sufficiently minimized. However, the error is the variation that exists between the predicted data and the experimental data. A well trained neural network has higher predictive ability [29]. Figure 1. shows how ANN is executed.

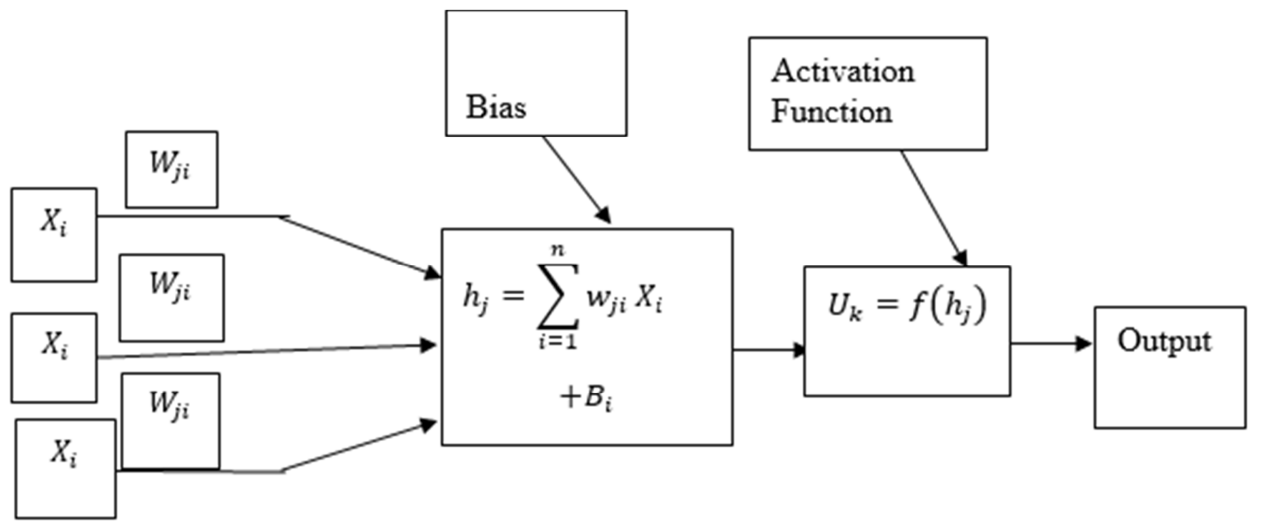

Figure 1. ANN computation process.

Where $U \kappa$ is the output, $W_{j i}$ weights of the hidden layer, $X_{i}$ are the values of the inputs, $B_{i}$ is the bias of the hidden layer neurons. In the ANN execution, the inputs were blend percentages, brake load and injection timings, while the outputs were brake thermal efficiency, brake specific energy consumption and exhaust gas temperature.

Tropical Almond (Terminalia catappa) is a tall deciduous and erect tree reaching 15-25 $\mathrm{m}$, trunk 1-1.5 $\mathrm{m}$ in diameter, often buttressed at the base. Its whorls are of nearly horizontal, slightly ascending branches spaced 1-2 m apart in tiers, or storeys, up the trunk. The pagoda-like habit becomes less noticeable as the branches elongate and droop at the tips. Its grey-brown bark becomes rough with age. Its fruit is hard to $7 \mathrm{~cm}$, green-red, rounded and flattened, egg-shaped, with 2 ridges but no wings, $2.5 \times 3-6 \mathrm{~cm}$ long, yellow or reddish when ripe. The cylindrical, oil-containing seeds are encased in a tough, fibrous husk within a fleshy pericarp. There are about 24 fresh fruits and 160 nuts per $\mathrm{kg}$. It grows best in moist tropical climates. The tree is well adapted to sandy and rocky coasts and flourishes on oolitic limestone. Terminalia catappa. seed oil is of unsaturated type and contains mainly the fatty acids oleic C18:1(31.48\%) and linoleic C18:2 $(28.93 \%)$. The oil can be classified in the oleic-linoleic acid group. The oil extracts exhibit good physicochemical properties and could be useful for industrial applications.

It is often difficult to investigate the performance characteristics of a compression ignition engine using experimental means. This is because it is either always too time consuming to set up the rig, or very costly to purchase the components. Therefore, this study was aimed at investigating the effect of injection timing on performance parameters (BTE, BSEC and Texh) using Artificial Neural Network. The novelty of this study is that it is the first in literature to make extensive description of the application of $\mathrm{ANN}$ in investigation the performance of CI engines operated on tropical almond biodiesel.

\section{Material and Method}

\subsection{Engine Test}

The performance test was conducted in a single cylinder four stroke diesel engine. Figure 2. shows the diagram of the experimental setup used for conducting the experiments. It consists of a single cylinder four stroke water cooled compression ignition engine connected to an eddy current dynamometer. The compression ratio was 17.5:1. The specifications of the engine are shown in Table 1.

Experiments were conducted initially by using neat diesel at various loads and then using tropical almond oil blends. Experiments were repeated by changing injection timings. Matrix of the experiments conducted is as shown in Table 2.

Table 1.Specifications of the Engine.

\begin{tabular}{ll}
\hline Engine & $\begin{array}{l}\text { Four stroke, single cylinder, water cooled, } \\
\text { constant speed diesel engine }\end{array}$ \\
\hline Rated power & $3.2 \mathrm{KW}$ \\
Speed & $1500 \mathrm{rpm}$ \\
Bore & $87.5 \mathrm{~mm}$ \\
Stroke & $110 \mathrm{~mm}$ \\
Compression ratio & $17.5: 1$ \\
Crank angle sensor & Resolution $1^{\circ}$ \\
Engine indicator & For data scanning \& interfacing with Pentium \\
Swept volume & III processor \\
\hline
\end{tabular}

Table 2.Experimental Conditions using tropical almond ester blends.

\begin{tabular}{llllll}
\hline Operating parameter & \multicolumn{7}{l}{ Variations } \\
\hline Engine Load (\%) & 0 & 25 & 50 & 75 & 100 \\
Tropical almond ester blend (\%) & 20 & 40 & 60 & 80 & 100 \\
Injection timing ( $\left.{ }^{\circ} \mathrm{bTDC}\right)$ & 21 & 24 & 27 & & \\
\hline
\end{tabular}




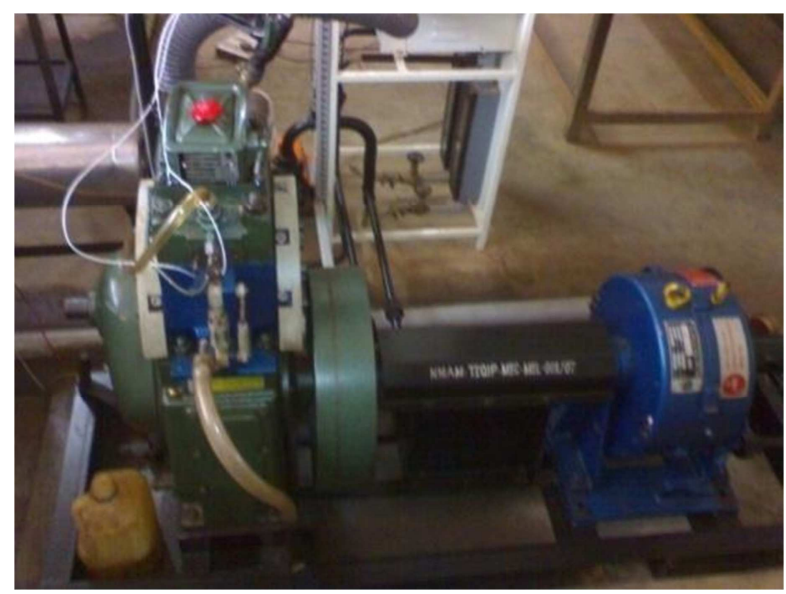

Figure 2. Experimental Setup.

\subsection{ANN Execution and the Performance Indicators}

An ANN model for the biodiesel engine was developed by using the steady state experimental data. In the model $70 \%$ of the experimental data were used for the training set, while the remaining $30 \%$ were employed for the test purpose. The inputs to the ANN were almond biodiesel blend percentage, load percentage, and the injection timing. The output parameters from the ANN were brake thermal efficiency (BTE), brake specific energy consumption, (BSEC) and exhaust gas temperature $\left(\mathrm{T}_{\mathrm{exh}}\right)$.

The input patterns are presented to the network as a normalized array and are scaled in the range of 0.1 to 0.9 . The original values are normalized for efficient processing by the network. The normalization is carried out using a linear mapping given by (1) as neural network was found to perform better in this range. [30,31].

$$
\frac{A_{L}-A_{\min }}{A_{\max }-A_{\min }} \mathrm{X}(\text { High - Low })+\text { Low }
$$

Where, $\mathrm{A}_{i}$ is the actual data, $\mathrm{A}_{\min }$ is minimum data value, $\mathrm{A}_{\max }$ is the maximum data value, high is the maximum normalized data which equals to 0.9 , and low is the minimum normalized data which equals to 0.1.Figure 3 shows the mode of execution of ANN.

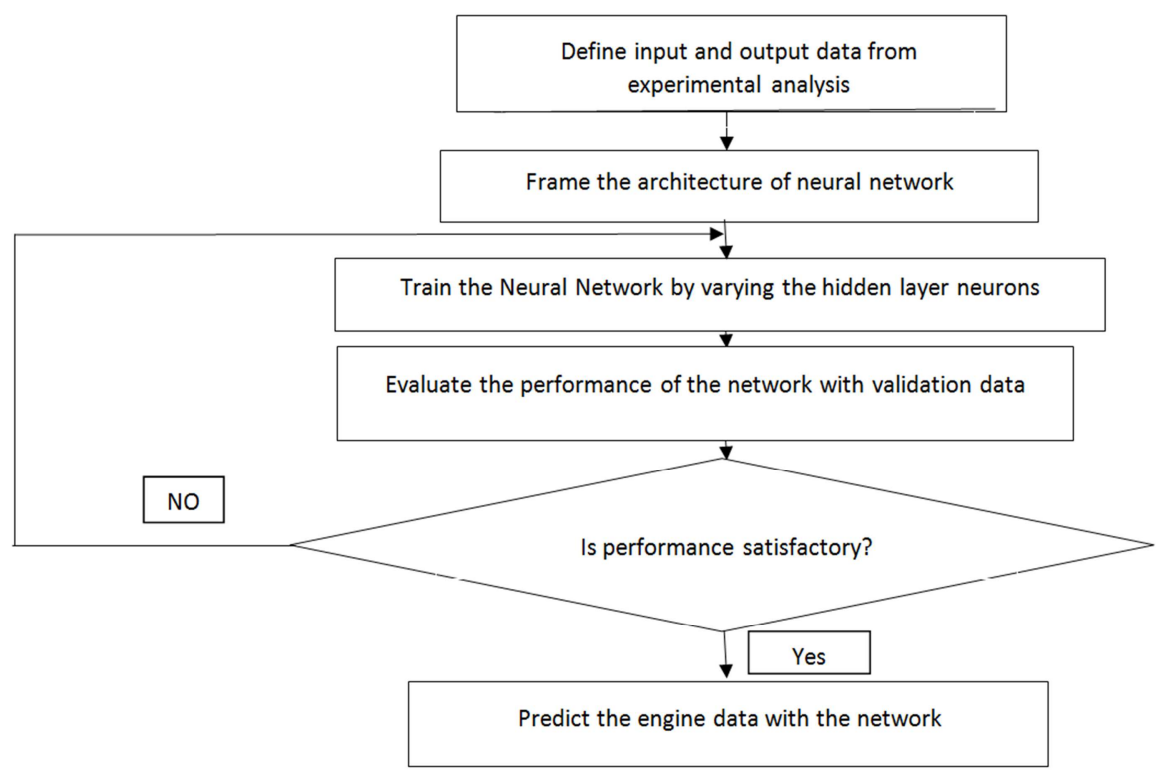

Figure 3. The stages involved in ANN model execution.

The network performance is measured through the correlation coefficient (R) and mean relative error values (MRE). The correlation coefficient is used to assess the strength of the relationship between the predicted and experimental values where $\mathrm{R}$ values closer to +1 indicate a stronger positive linear relationship, while $\mathrm{R}$ values closer to -1 indicate a stronger negative relationship. The mean relative error (MRE), which shows the mean ratio between the error and the experimental values, and R are shown in (2) and (3).

$$
\begin{gathered}
M A P E=\frac{1}{n} \sum_{i=1}^{n}\left|\frac{a_{i}-p_{i}}{a_{i}}\right| \times 100 \\
R=\frac{\sum_{i=1}^{n}\left(a_{i}-\tilde{a}_{i}\right)\left(p_{i}-\tilde{p}_{i}\right)}{\sqrt{\sum_{i=1}^{n}\left(a_{i}-\tilde{a}_{i}\right)^{2} \cdot \sum_{i=1}^{n}\left(p_{i}-\tilde{p}_{i}\right)^{2}}}
\end{gathered}
$$

Where $\mathrm{n}$ is the number of points in the data set, ' $\mathrm{a}$ ' and ' $\mathrm{p}$ ' are actual and predicted output sets respectively [32,33]. Finally, the root mean square error is obtained from (4).

$$
R M S E=\sqrt{\frac{1}{n} \sum_{i=1}^{n}\left(a_{i}-p_{i}\right)^{2}}
$$

\section{Results and Discussion}

\subsection{Brake Thermal Efficiency (BTE)}

(a) in Figure (4) indicates the variation of BTE with injection timings. Results indicated $20 \%$ blend of Tropical almond ester in diesel hasmaximum efficiency. Efficiency was found to be decreasing for higher blend proportions. This may be due to the decrease in the calorific value of the blend 
for increased blend proportions. On advancing the injection timing there was an increase in the delay period which reduced the thermal efficiency. At retarded injection timing the delay period decreased which reduced the power because larger amount of fuel burns during expansion.

The ANN model for BTE $21^{\circ} \mathrm{bTDC}$ injection timing yielded a correlation coefficient $(\mathrm{R})$ of 0.9976 , mean relative error (MRE) of $2.48 \%$, and root mean square error (RMSE) of $1.02 \%$ as shown in (b) in Figure (4). The predicted values of BTE as a function of experimental values at $24^{\circ} \mathrm{bTDC}$ injection timing are shown in (c) in Figure (4). A correlation coefficient (R) of 0.996 , MRE of $0.24 \%$ and RMSE of $0.958 \%$ was generated by the ANN model. (d) in Figure (4) represents the values of BTE as a function of experimental values at $27^{\circ} \mathrm{bTDC}$ injection timing. A correlation coefficient (R) of 0.998, MRE of $3.39 \%$ and RMSE of $0.879 \%$ are shown by the ANN model.

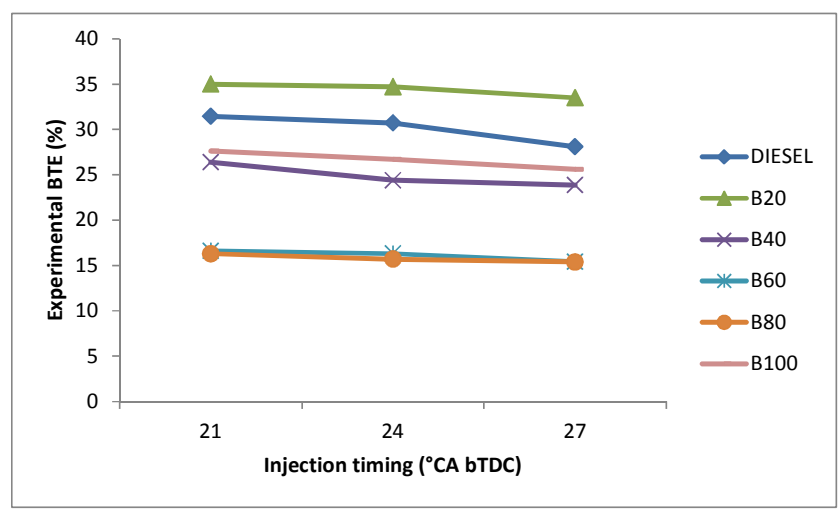

(a)

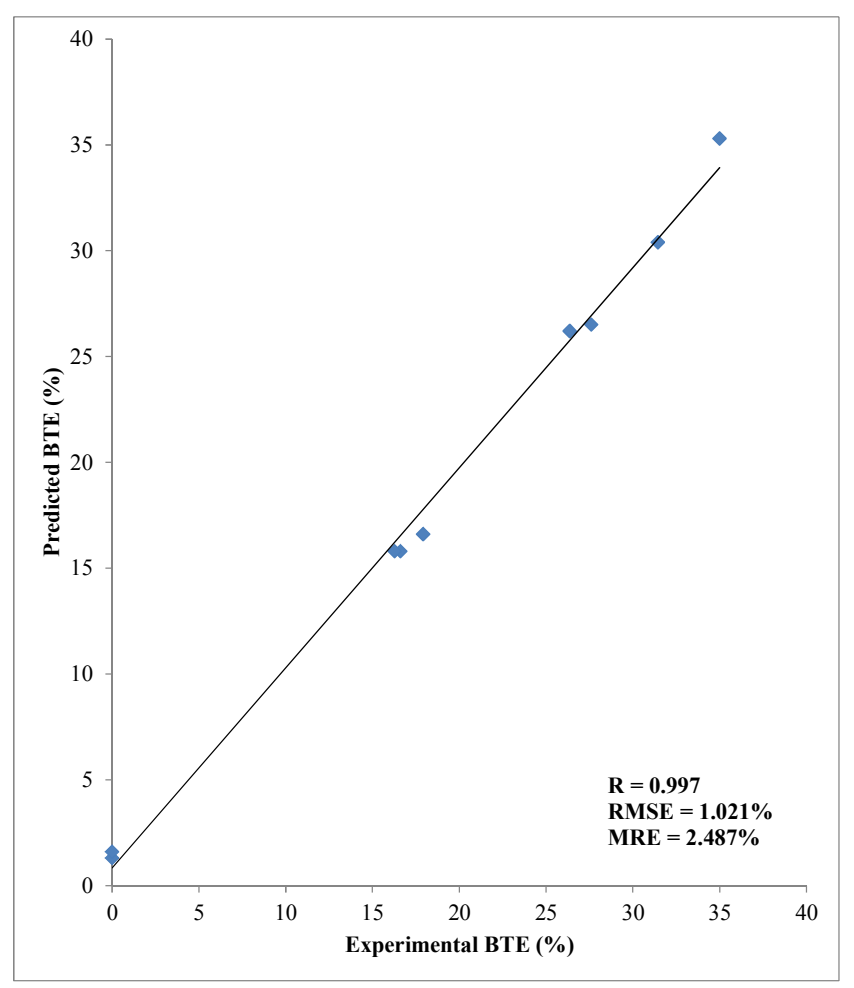

(b)

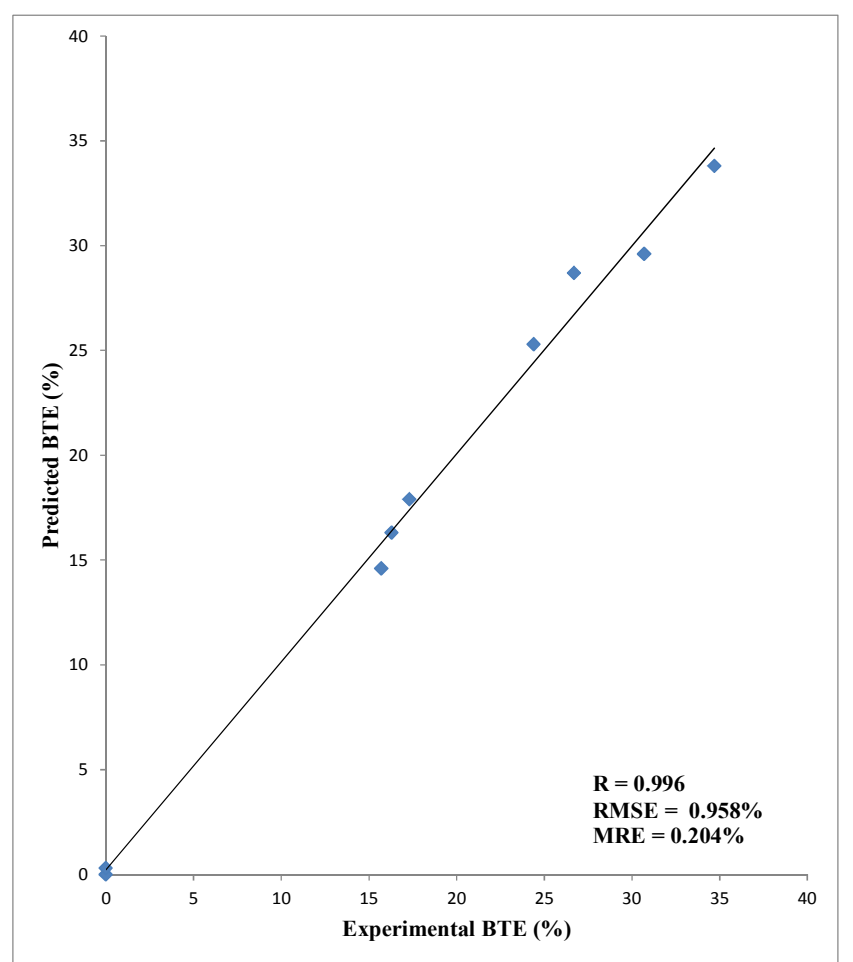

(c)

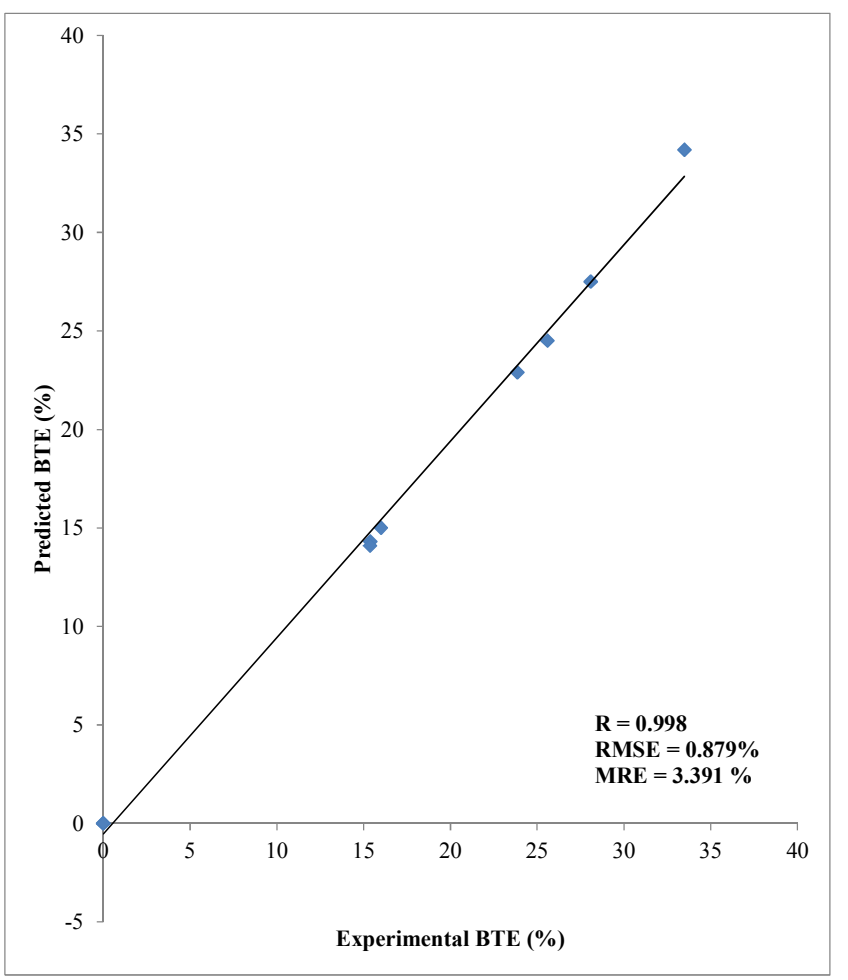

(d)

Figure 4. ANN predicted against experimental values for BTE at different injection timings, $21^{\circ} B T D C, 24^{\circ} B T D C$ and $27^{\circ} B T D C$.

\subsection{Exhaust Temperature $\left(T_{e x t}\right)$}

(a) in Figure (5) shows the variation in exhaust gas temperature with injection timings. As the combustion is delayed, injected almond biodiesel fuel particles may not get 
enough time to burn completely before TDC, hence some fuel mixtures tends to burn during the early part of expansion, consequently after burning occurs and hence increase in the exhaust temperature. With respect to the injection timings, advanced injection timing showed highest Texh. Retarding the injection timing has caused earlier start of combustion relative to TDC and hence complete combustion will take place and thus reducing the exhaust gas temperatures showing efficient combustion.

The ANN shows MRE of $0.025 \%$, RMSE of $0.826^{\circ} \mathrm{C}$ and $\mathrm{R}$ of 0.999 at $21^{\circ} \mathrm{bTDC}$ injection timing as shown in (b) in Figure (5). The values predicted by ANN model and the experimental values for Texh at $24^{\circ} \mathrm{bTDC}$ injection timing are shown in (c) in Figure (5). The ANN model showed an MRE of $0.591 \%$, RMSE of $4.012^{\circ} \mathrm{C}$ and $\mathrm{R}$ of 0.999 . The ANN predicted values and experimental values for exhaust gas temperature at $27^{\circ} \mathrm{bTDC}$ injection timing are shown in (d) in Figure (5). The ANN model showed MRE of $0.448 \%$, RMSE of $3.57^{\circ} \mathrm{C}$ and $\mathrm{R}$ of 0.992 .

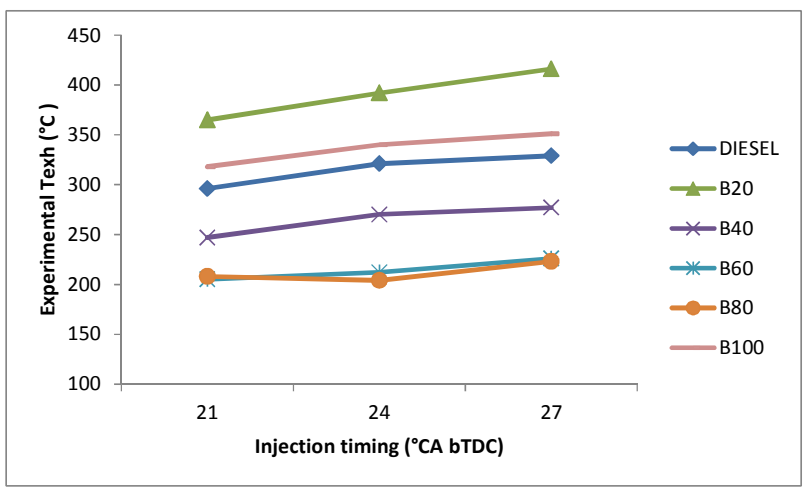

(a)

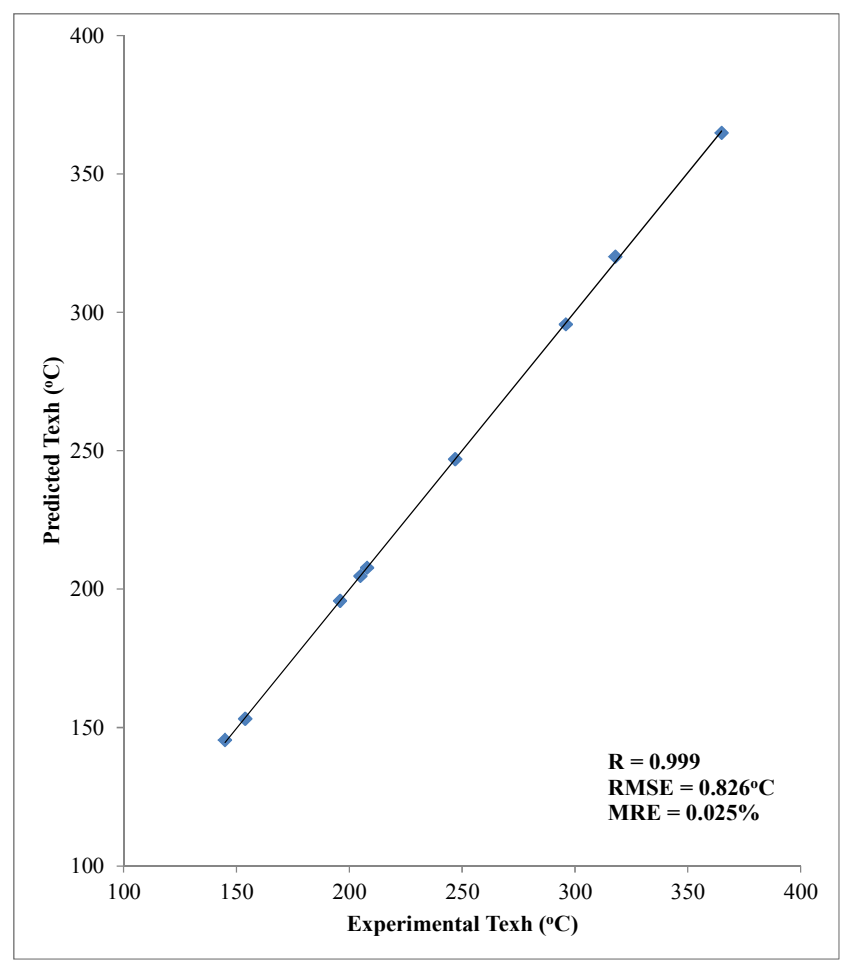

(b)

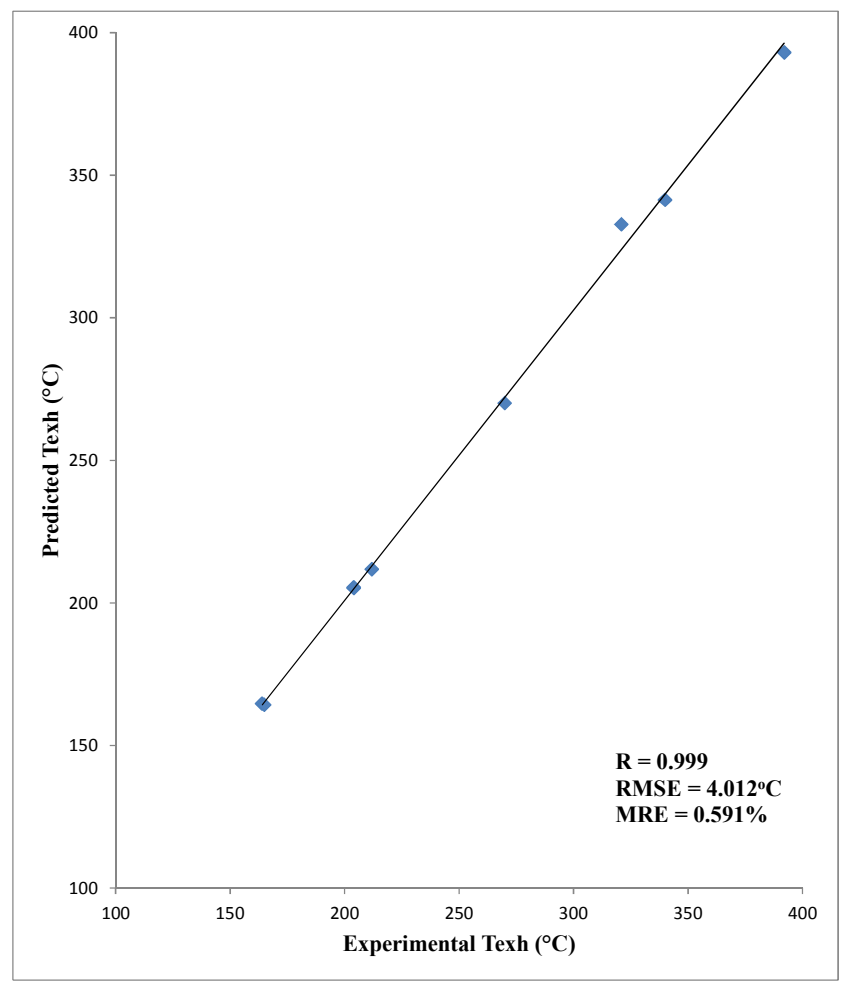

(c)

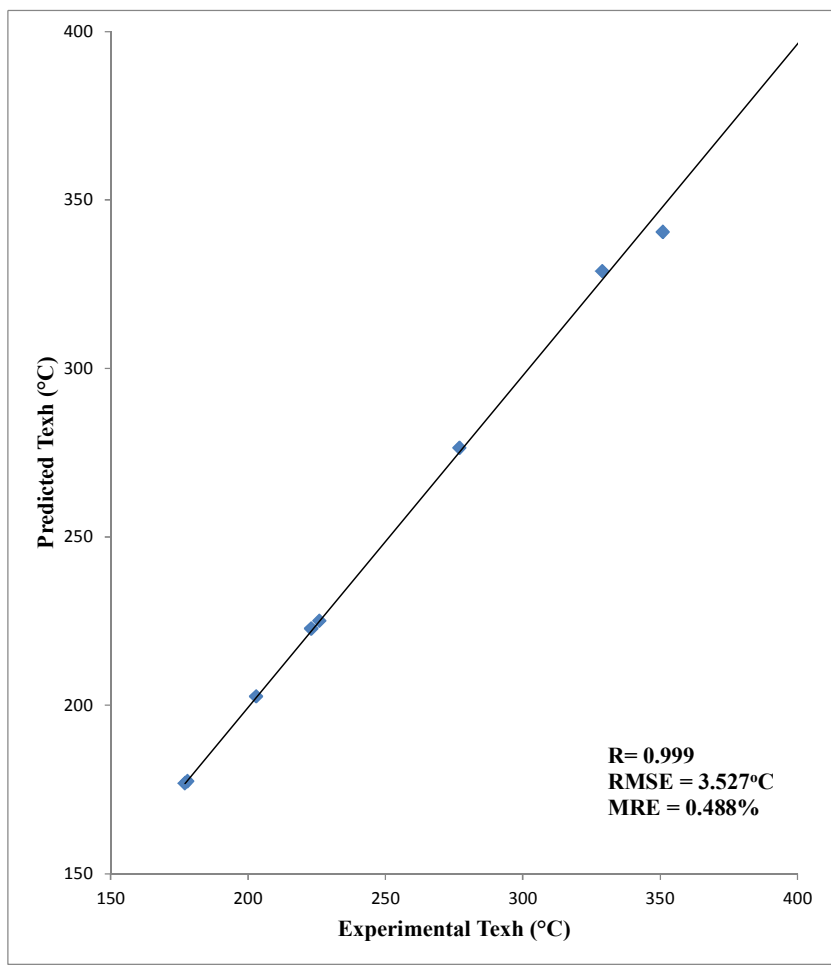

(d)

Figure 5. ANN predicted against experimental values for $T_{\text {exh. at different }}$ injection timings, $21^{\circ} B T D C, 24^{\circ} B T D C$ and $27^{\circ} B T D C$.

\subsection{Brake Specific Energy Consumption (BSEC)}

(a) in Figure (6) shows the variation of BSEC for different injection timings. BSEC decreased with load for diesel as well as Tropical Almond ester blends. For 20\% blend the 
BSEC value was minimum compared with other blends, but higher than that for neat diesel. Advancing the injection by $3^{\circ}$ reduced BSEC by $2.9 \%$, and retarding the injection by $3^{\circ}$ increased BSEC by $5.2 \%$.

The ANN model prediction for BSEC at 21obTDC generated a correlation coefficient of 0.981 as shown in (b) in Figure (6). It was observed that the MRE value was $0.278 \%$ and the RMSE value was $0.436 \mathrm{KJ} / \mathrm{KWh}$. (c) in Figure (6) revealed that the prediction of BSEC was in good agreement with actual values. A correlation coefficient of 0.963 was obtained for BSEC at 24obTDC. From (d) in Figure (6) the MRE value was $7.207 \%$ and the RMSE value was $1.081 \mathrm{KJ} / \mathrm{KWh}$. The ANN model prediction for BSEC at 27obTDC gave a correlation coefficient of 0.965 . The MRE value was found to be $0.221 \%$ while the RMSE value was $0.978 \mathrm{KJ} / \mathrm{KWh}$.

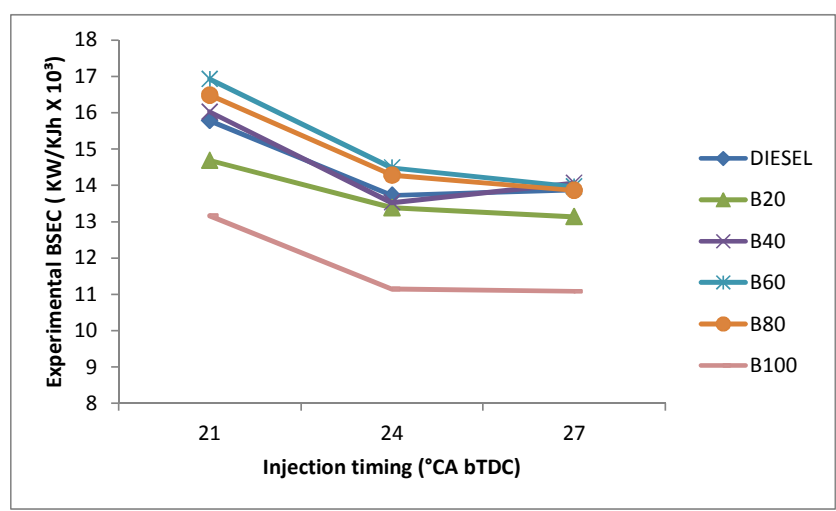

(a)

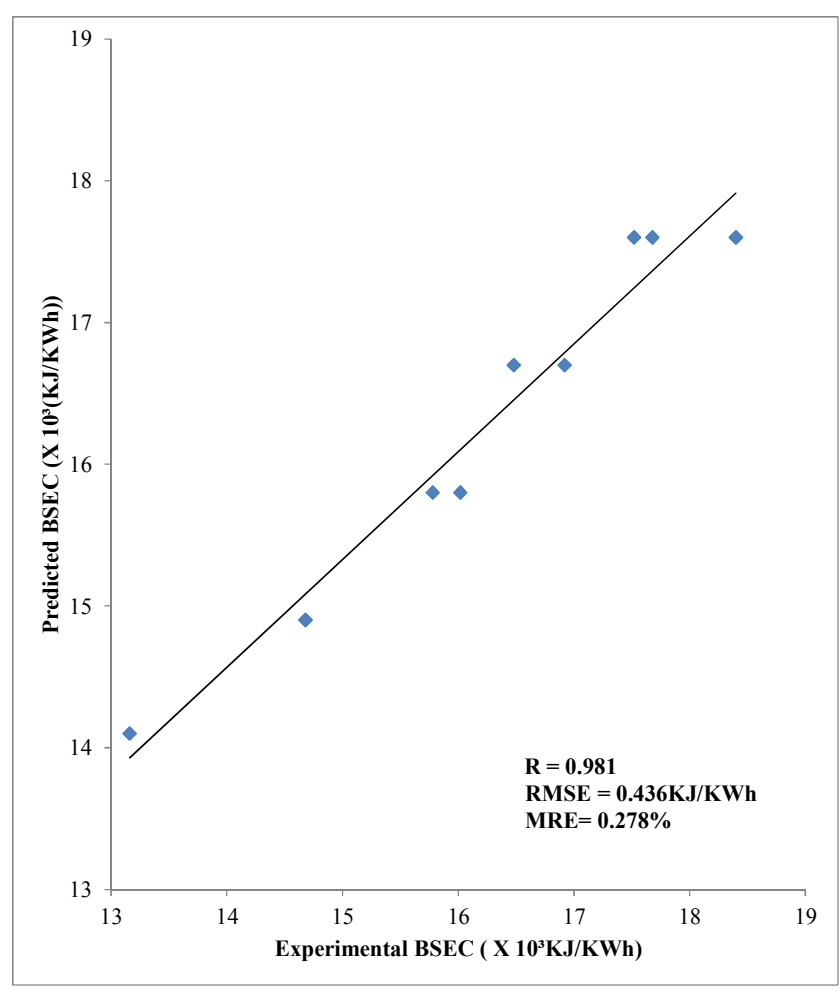

(b)

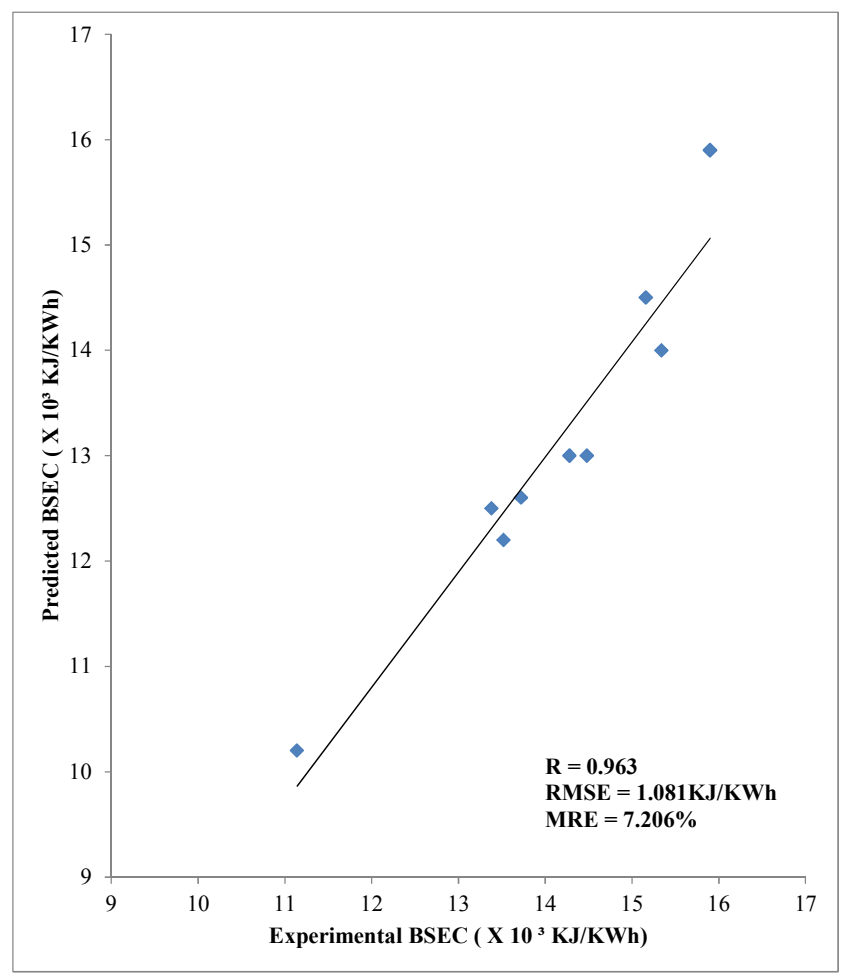

(c)

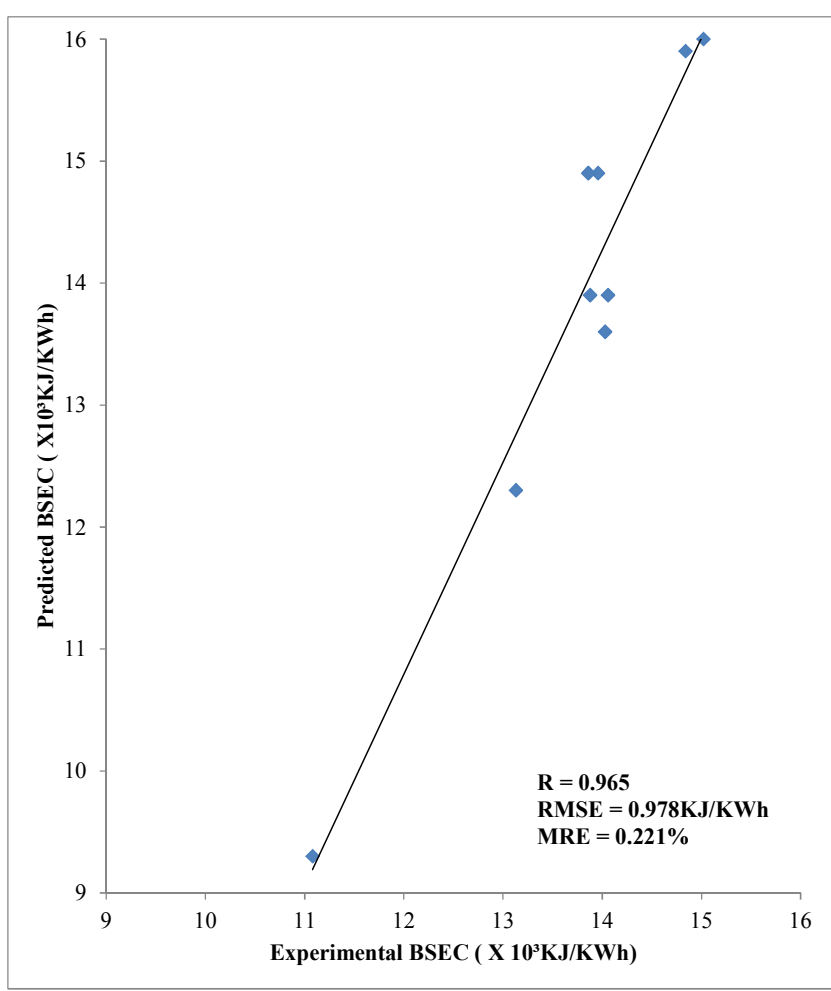

(d)

Figure 6. ANN predicted against experimental values for BSEC at different injection timings, $21^{\circ} B T D C, 24^{\circ} B T D C$ and $27^{\circ} B T D C$.

\section{Conclusion}

After intensive assessment of the performance characteristics of compression ignition engine operated by 
tropical almond ester blends using artificial neural network model of feed forward back propagation multilayer perceptron, the following core conclusions were reached:

Brake thermal efficiencies of biodiesel engine operated on Tropical Almond ester blends are very close to diesel and the $20 \%$ blend with diesel has shown maximum efficiency for biodiesel operation for all injection timings.

Brake specific energy consumption for biodiesel blends is more than that of diesel. With respect to the injection timings, retarding the injection timing from $24^{\circ}$ bTDC increased the BSEC values.

Retarding the injection timing reduces the exhaust gas temperatures which shows efficient combustion.

ANN modeling was applied to predict the performance characteristics of a four stroke CI engine. It was observed that MRE of the test data for the performance and emission parameters were within $10 \%$, which is acceptable.

The developed ANN model has been found to be useful for the prediction of engine performance parameters. This reduces the experimental efforts and hence can serve as an effective tool for predicting the performance of the engine and emission characteristics under various operating conditions with different biodiesel blends.

\section{References}

[1] Deepak. A, Lokesh. K, Avinash. K. A. (2008). Performance evaluation of a vegetable oil fuelled compression ignition engine. Renew. Energy 33:1147-1156.

[2] Baiju. B, Naik. M. K, Das. L. M (2009). Comparative evaluation of Compression ignition characteristics using methyl and ethyl esters of Karanja oil. Renew. Energy 34:1616-1621.

[3] Surendra. R. K (2010). Plant oils as fuels for C.I engines - A technical review and life cycle analysis. Renew. Energy 35:113.

[4] Mustafa Cranakci. 2007. Combustion characteristics of a turbocharged DI compression ignition engine fuelled with petroleum diesel fuels and biodiesel. Bioresource technology 98 (2007) 1167-1175.

[5] Wai-Hong Leong, Jun-Wei Lim, Man-Kee Lam, Yoshimitsu Uemura, Yeek-Chia Ho. Thirdn generation biofuels: a nutritional perspective in enhancing microbial lipid production. Renewable and sustainable energy reviews 91(2018) 950-961.

[6] Purushathaman. K. and Nagarajan. G. 2009. Performance, emission and combustion characteristics of a compression ignition engine operating on neat orange oil. Renewable energy 34 (2009) 242-245.

[7] Patrick Akpan and Paul Ozor. 2014. An estimation of orange oil (Biodiesel) quantity from orange peel in Nigeria. NIIE 2014 conference proceedings.

[8] Bawadi Abdullah, Syed Anuar Faua'ad Syed Muhammad, Zahra Shokravi, Shahrul Ismail, Khairul Anuar Kassim, Azmi Nik Mahmood, Md Maniruzzaman A. Aziz. Fourth generation biofuel: a review on risks and mitigation strategies. Renewable and sustainable energy reviews 107 (2019) 37-50.
[9] Kifayat Ullah, Vinod Kumar Sharma, Mushtaq Ahmed, Pengmei Lv, Jurgen Krahl, Zhongming Wang, Sofia. The insight views of advanced technologies and its application in bio-origin fuel synthesis from lignocellulose biomasses waste, a review. Renewable and sustainable energy reviews (2017).

[10] Ali Abdulkhani, Peyman Alizadeh, Sahab Hedjazi, Yahya Hamzeh. Potential of soya as a raw material for a whole crop biorefinery. Renewable and sustainable energy reviews (2016).

[11] Prasanna Borse, Amol Sheth. Technological and commercial update for first-and second-generation ethanol production in India. Springer international publishing $A G$ 2017. DOI 10.1007/978-3-319-50219-9_13.

[12] Daniela L. Aguilar, Rose, Rose M. Rodriguez-Jasso, Elisa Zanuso, Anely A. Lara-Flores, Cristobal N. Aguilar, Arturo Sanchez, Hector A. Ruiz. Operational strategies for enzymatic hydrolysis in a biorefinery. Springer international publishing $A G \quad 2018$. https://doi.org/10.1007/978-3-319-67678-4_10.

[13] Oladapo Martins Adeniyi, Ulugbek Azimov, Alexery Burluka. Algae biofuel: current status and future applications. Renewable and sustainable energy reviews 90 (2018) 316335 .

[14] Poonam Singh Nigam, Anoop Singh. Production of liquid biofuels from renewable resources. Progress in energy and combustion science 37 (2011) 52-68.

[15] Man Lee Lam, Keat Teong Lee. Microalgae biofuels: a critical review of issues, problems and the way forward. Biotechnology advances 30 (2012) 673-690.

[16] Francesco Cherubini. The biorefinery concept: using biomass instead of oil for producing energy and chemical. Energy conversion and management 51 (2010) 1412-1421.

[17] S. N. Naik, Vaibhav V. Goud, Prasant K. Rout, Ajay K. Dalai. Production of first and second generation biofuels: a comprehensive review. Renewable and sustainable energy reviews 14 (2010) 578-597.

[18] Roman A. Voloshin, Margarita V. Rodionova, Sergey K. Zharmukhamedov, T. Nejat Veziroglu, Suleyman I. Allakhverdiev. Review: biofuel production from plant and algae biomass. International journal of hydrogen energy (2016) 1-17.

[19] Cenk. S, Kadir. U, Mustafa. C (2008). Influence of injection timing on the exhaust emissions of a dual fuel CI engine. Renewable. Energy 33:1314- 1323.

[20] Nwafor O. M. I (2007). Effect of advanced injection timing on theemission characteristics of a diesel engine running on natural gas. Renew. Energy 32:2361-2368.

[21] B. Ashok, K. Nanthagopal, D. Arumuga Perumal, J. M. Babu, Anmol Tiwari, Akhil Sharma. An investigation on CRDi engine characteristic using renewable orange-peel oil. Energy conversion and management 180 (2019) 1026-1038.

[22] B. Ashok, K. Nanthagopal, B. Saravanan, P. Somasundaram, C. Jegadheesan, Bhaskar Chaturvedi, Shivam Sharma, Gaurang Patni. A novel study on the effect lemon peel oil as a fuel in CRDI engine at various injection strategies. Energy conversion and management 172 (2018) 517-528. 
[23] A. Naresh Kumar, Dr. K. Brahma Raju, Dr. P. Srinivas Kishore, K. Narayana. Some experimental studies on effect of exhaust-gas recirculation on performance and emission characteristics of a compression-ignition engine fuelled with diesel and lemon-peel oil blends. Materials today: proceedings 5(2018) 6138-6148.

[24] B. Ashok, K. Nanthagopal, Bhaskar Chaturvedi, Shivam Sharma, R. Thundil. A comparative assessment on common rail direct injection (CRDI) engine characteristics using low viscous biofuel blends. Applied thermal engineering (2018).

[25] Subrata Bhowmik, Rajsekhar Panua, Subrata Kumar Ghosh, Durbadal Debroy, Abhishek Paul. 2017. A comparative study of Artificial Intelligence based models to predict performance and emission characteristics of a single cylinder Diesel engine fueled with Diesosenol. Journal of thermal science and engineering application.

[26] O guz, H, Sarıtas. I, and Baydan. H. E., 2014. Prediction of diesel engine performance using biofuels with artificial neural network. Expert system application 37(9), pp. 6579-6586.

[27] Rezaei. J, Shahbakhti. M, Bahri.B, and Aziz.A. A. Performance prediction of HCCI engines with oxygenated fuels using artificial neural networks. Applied. energy, 138, pp. 460-473.
[28] Togun N. K and Baysec S. Prediction of torque and specific fuel consumption of a gasoline engine by using artificial neural Networks. Applied Energy 2010; 87: 349-355.

[29] Abhishek Sharma, Praderpta Kumar Sahoo, R. K. Tripath, and Lekha Charan Meher. ANN based prediction of performance and emission characteristics of CI engine using polanga as a biodiesel. International journal of ambient energy.

[30] Adnan Qadir, Mansoor Imam (2006). Utilisation of waste plastic bags inbituminous mix for improved performance of roads.Journal of Solid Waste Technology and Management, Vol.32, No.3.

[31] Nasr. G.E, Badr. E. A, Joun. C, 2003. Backpropagation neural networks for modelling gasoline consumption, energy convers. Manage, 44, 893-905.

[32] Sayin, C., Ertunc, H.M., Hosoz, M., Kilicaslan, I. Canakci, M. Performance and exhaust emissions of a gasoline engine using artificial neural network.Applied Thermal Engineering, Vol. 27,No.1, pp. 46-54, 2007.

[33] Yusuf Kurtgoz, Mustafa Karagoz, Emrah Deniz. 2018. Biogas engine performance estimation using ANN. Engineering science and technology, an international journal. 